\title{
ACCIÓN DEL CICR EN LÍBANO
}

Comunicado de prensa del 25 de mayo de 1976:

Para poder proseguir y ampliar su acción humanitaria en Líbano durante los 4 meses próximos, el Comité Internacional de la Cruz Roja ha hecho un acuciante llamamiento a los Gobiernos y a las Sociedades nacionales de la Cruz Roja y de la Media Luna Roja para recaudar fondos.

En el llamamiento se destaca que se requieren 21 millones de francos suizos para aprovisionar los hospitales libaneses adonde continúan afluyendo los heridos y donde con frecuencia se carece de los medicamentos básicos y de equipo médico. Además, unos 150.000 libaneses necesitan urgente ayuda alimentaria y médica.

La mayor parte de ellos son personas desplazadas que han perdido su vivienda a causa de los combates.

Hasta la fecha, el CICR ha enviado a Líbano 350 toneladas de socorros, aproximadamente, en especial medicamentos, por un valor superior a los 6 millones de francos, y que han sido distribuidos a todas las partes en conflicto.

El personal contratado por el CICR para la acción en Líbano está integrado por 25 delegados, de los cuales 11 médicos y enfermeras de las Cruces Rojas escandinavas, a cuyo cargo corre el hospital de campaña del CICR en Beirut. 